Gill, S.; Kockar, I.; Ault, G.W., "Dynamic Optimal Power Flow for Active Distribution Networks," Power Systems, IEEE

Transactions on, vol.PP, no.99, pp.1,11

\title{
Dynamic Optimal Power Flow for Active Distribution Networks
}

\author{
S. Gill IEEE student member, I. Kockar, IEEE Member, and G. W. Ault, IEEE Member
}

\begin{abstract}
Active Network Management is a philosophy for the operation of distribution networks with high penetrations of renewable distributed generation. Technologies such as energy storage and flexible demand are now beginning to be included in Active Network Management (ANM) schemes. Optimizing the operation of these schemes requires consideration of intertemporal linkages as well as network power flow effects. Network effects are included in Optimal Power Flow (OPF) solutions but this only optimizes for a single point in time. Dynamic Optimal Power Flow (DOPF) is an extension of OPF to cover multiple time periods. This paper reviews the generic formulation of Dynamic Optimal Power Flow before developing a framework for modeling energy technologies with inter-temporal characteristics in an ANM context. The framework includes the optimization of nonfirm connected generation, Principles of Access for non-firm generators, energy storage and flexible demand. Two objectives based on maximizing export and revenue are developed and a case study is used to illustrate the technique. Results show that DOPF is able to successfully schedule these energy technologies. DOPF schedules energy storage and flexible demand to reduce generator curtailment significantly in the case study. Finally the role of DOPF in analyzing ANM schemes is discussed with reference to extending the optimization framework to include other technologies and objectives.
\end{abstract}

Index Terms-Energy storage, Flexible demand, Active Network Management, OPF, dynamic optimal power flow

\section{NOMENCLATURE}

\section{General DOPF}

$\begin{array}{ll}\boldsymbol{x} & \text { Vector of OPF control variables } \\ \boldsymbol{y} & \text { Vector of OPF fixed parameters } \\ \boldsymbol{\tau} & \text { Vector of intertemporal variables } \\ \boldsymbol{z} & \text { Vector of OPF derived variables } \\ \boldsymbol{f} & \text { Objective function } \\ \boldsymbol{g} & \text { OPF equality constraints } \\ \boldsymbol{h} & \text { OPF inequality constraints } \\ \boldsymbol{k} & \text { Intertemporal equality constraints } \\ \boldsymbol{l} & \text { Intertemporal inequality } \\ & \text { constraints }\end{array}$

This work is partly funded through the in Wind Energy Systems Centre for Doctoral Training at the University of Strathclyde. EPSRC EP/G037728/1.

S. Gill is with the Wind Energy Systems CDT, University of Strathclyde, Glasgow, G1 1XW, UK (email: simon.gill@ strath.ac.uk)

$\begin{array}{cl}g c p & \text { Grid Connection Point number } \\ g c p_{n} & \begin{array}{l}\text { Number of Grid Connection } \\ \text { Points }\end{array} \\ P_{g c p}, P_{g c p}^{\min }, P_{g c p}^{\max } & \begin{array}{l}\text { Power injection from grid } \\ \text { connection point and limits on } \\ \text { power from grid connection point }\end{array} \\ Q_{g c p}, Q_{g c p}^{\min }, Q_{g c p}^{\max } & \begin{array}{l}\text { Reactive power injection from } \\ \text { grid connection point and limits }\end{array} \\ & \text { on reactive power from grid } \\ & \text { connection point } \\ t & \text { Time-step } \\ \Delta t & \text { Length of time step } \\ t_{n} & \text { Number of time-steps in } \\ t^{\prime} & \text { optimization } \\ b, b_{n} & \text { Summation step-time variable } \\ V, V_{\min }, V_{\max } & \text { Bus number, number of busses } \\ l, l_{n} & \text { Bus Voltage and voltage limits } \\ S, S_{\max } & \text { Line number, number of lines } \\ n f & \text { Apparent line power flow and } \\ n f_{n} & \text { apparent power limit } \\ i, j & \text { Non-firm generator number } \\ P_{g}, P_{g}^{\max } & \text { number of non-firm generator } \\ & \text { Indices of non-firm generator } \\ k & \text { number } \\ & \text { Non-firm power output, and } \\ & \text { maximum non-firm generator } \\ \text { output } & \text { Priority order scaling constant } \\ & \text { Priority order number } \\ \text { Vector of external power prices }\end{array}$

Energy Storage System (ESS)

$\varepsilon_{\text {in }}, \varepsilon_{\text {out }} \quad$ Input and output ESS efficiency

SOC ESS State of Charge

SOC ${ }^{\min }, S O C^{\max } \quad$ Permissible state of charge limits

I. Kockar and G. Ault are with the Institute for Energy and Environment, University of Strathclyde, Glasgow, G1 1XW, UK (emails: ivana.kockar@strath.ac.uk; graham.ault@strath.ac.uk) 


$\begin{array}{cl}P_{E S S} & \text { Power injected into grid by ESS } \\ P_{E S S}^{\text {charge }} & \begin{array}{l}\text { Power injected into grid by ESS } \\ \text { when charging (negative) }\end{array} \\ P_{E S S}^{\text {dis }} & \begin{array}{l}\text { Power injected into grid by ESS } \\ \text { when discharging (positive) }\end{array} \\ P_{E S S}^{\text {rated }} & \text { ESS rated power } \\ Q_{E S S} & \text { Reactive Power injection from } \\ & \text { PSS } \\ E_{E S S}^{\text {cap }} & \text { Energy capacity of ESS }\end{array}$

Flexible Demand

$\begin{array}{cl}P_{D M F D}, P_{S M F D} & \begin{array}{l}\text { Power injected into grid by } \\ \text { flexible demand units (negative) }\end{array} \\ P_{D M F D}^{\text {rated }}, P_{S M F D}^{\text {rated }} & \begin{array}{l}\text { Rated power of flexible demand } \\ \text { units }\end{array} \\ E_{S M F D}^{\text {cap }} & \text { Energy storage capacity of SMFD } \\ P_{\text {heat }} & \text { Demand to extract heat from } \\ & \text { SMFD } \\ E_{D M F D}, E_{S M F D} & \begin{array}{l}\text { Total energy demand of flexible } \\ \text { demand units across optimization }\end{array} \\ S O C_{S M F D} & \begin{array}{l}\text { State of Charge of storage } \\ \text { managed flexible demand }\end{array} \\ S_{S O C_{S M F D}^{\min }, S O C_{S M F D}^{\max }} & \begin{array}{l}\text { Minimum and maximum levels of } \\ \text { State of charge }\end{array} \\ \mu & \text { Efficiency / coefficient of } \\ & \text { performance for storage managed } \\ & \text { flexible demand }\end{array}$

\section{INTRODUCTION}

$\mathrm{T}^{\mathrm{s}}$ The operation of power systems has for a long time been informed by Optimal Power Flow (OPF) [1]. The process is used to dispatch available generation plant in a way that minimizes a particular objective function. OPF can fully represent the network equations and nodal power balance. It also maintains limits on bus voltage, branch power flows and generator outputs. Standard OPF formulations include minimizing operating costs and minimizing network losses. Other objectives have been developed to include minimizing emissions [2], and maximizing renewable penetration in distribution network [3],[4]. The algorithms used to solve OPF problems include both mathematical programming techniques and heuristic optimization [5],[6].

OPF is used to optimize for a particular point in time; to extend the problem in the time domain requires an extension of the basic OPF format. Intertemporal or Dynamic Optimal Power Flow (DOPF) was initially developed as an optimization in hydro-thermal power system problems, where stored energy can be dispatched at different times, but operation at one time affects the ability to operate at other times [7], [8]. DOPF solves the general problem of how to optimally dispatch generation across a network and across a time-horizon to meet demand within that time-horizon. It allows the modeling of 'intertemporal' technologies and effects including energy storage, flexible demand and generator ramp rates. A number of investigations using DOPF are presented in the literature. This includes interruptible demand investigated as part of an electricity market [9], the combination of markets for power and ancillary services [10], active and reactive power dispatch from energy storage [11] and the operation of energy storage and wind generation [12], [13].

An area where inter-temporal technologies are being deployed is the management of distribution networks (DNs). Active Network Management (ANM) is the philosophy of planned and real-time management of a $\mathrm{DN}$ and connected devices [14],[15]. It is being driven by the pressure to increase the penetration of renewable generation connecting to the power system as Distributed Generation (DG). Traditional operation of DNs assumes a 'fit-and-forget' strategy which significantly limits DG penetration [16]. ANM allows additional DG to connect under non-firm connection agreements and applies curtailment to these generators to maintain network constraints [17],[18]. Technologies such as Energy Storage Systems (ESS) [19] and flexible demand [20], both of which are inter-temporal are now forming important parts of ANM schemes.

ANM technologies help Distribution Network Operators (DNOs) deal with the variability of generation from renewable DG technologies such as wind, and its lack of correlation with demand. The optimization of ANM schemes containing intertemporal technologies and non-firm DG is an open problem, and DOPF can provide an important tool for analysis of these problems.

This paper lays out a full framework for the development of a general DOPF for use with Active Network Management schemes. It formulates AC DOPF as a non-linear (NL) programming problem including generation curtailment with Principles of Access, as well as ESS and flexible demand in an ANM context. The key contributions of this paper are as follows: firstly the full AC DOPF for ANM schemes is the first application DOPF in a way that fully models existing and developing ANM schemes; secondly it presents a method of encoding Principles of Access for non-firm generators within a DOPF; thirdly it is the first presentation of a DOPF which fully models both efficiency and the flexibility of an ESS; fourthly it presents a model of flexible demand linked to heat-storage; finally it discusses the optimization of ANM schemes over a 1day timescale.

\section{ACtive Network MANAGEMENT}

Over the past decade the ANM concept has been deployed in a number of $R \& D$ and pilot projects [21]. Current projects and future plans are moving beyond the simple model of realtime monitoring and control to day-ahead scheduling of technologies such as ESS and flexible demand [20].

The objective of ANM to date has been to maximize the ability of distribution networks to use renewable DG. They attempt to increase the efficiency with which existing assets are used. This section describes the key technologies relevant to ANM with an emphasis on inter-temporal effects.

\section{A. Generation Curtailment}

Under 'fit-and-forget' the maximum DG capacity is limited by power flow constraints, either thermal line limits or bus- 
voltage limits. The capacity limit is the maximum local generation that the network can accommodate whilst respecting power flow constraints during all non-fault operating scenarios. This 'firm generation' can be allowed to operate at all times at any level of output.

An ANM scheme provides the necessary communications and control infrastructure to allow additional 'non-firm' connections for DG under the requirement that the output of these new generators will be curtailed under instruction from the DNO. Curtailment will be applied to avoid breaching power flow constraints, and is likely when both demand is low and firm generation is high. Under these circumstances, network branches will be close to full capacity and there is no networkcapacity for additional generation [16].

ANM schemes allow the network operators to monitor and provide control signals to DGs in real-time. In the UK, the Orkney ANM scheme monitors and controls real-time generation curtailment to ensure thermal and voltage limits are maintained across the network and on undersea cables linking the distribution and transmission networks [17],[18].

\section{B. Non-firm Principles of Access}

When multiple non-firm generators connect, the remaining network capacity is shared out according to a particular Principle of Access (PoA) [22]. These are sets of rules defining which generator can access the limited network capacity. An example is a priority PoA where each generator has a fixed priority number and network access is always given to high priority generators first. This principle of access has been deployed as 'Last-In-First-Out' (LIFO) with priority decided by the order of connection.

Other examples of PoA include 'shared percentage' where all generators are curtailed by the same fraction of their output and 'technical-best' where the generators which allow the network to best meet its objectives are used.

\section{Energy Storage Systems}

ESSs provide a way of time-shifting energy from times suitable for generation to times where it is most useful. In an ANM scheme ESSs can be dispatched to reduce curtailment or manage network congestion. A number of technologies are available with the ability to time-shift multi-MWh quantities of energy over periods of hours or longer [23]. These include chemical batteries, pumped storage hydro schemes and compressed air.

ESS units such as chemical batteries operate with a powerelectronic interface linking the device to the electrical grid. These interfaces have been shown to be able to generate or consume reactive power whilst continuing to charge or discharge [24]. So called 'four-quadrant operation' requires a constraint on apparent power and providing reactive power support will reduce the capacity for real power charging and discharging.

\section{Flexible Demand}

Demand flexibility can be achieved in several ways, through response to price signals or by managing the delivery of energy. This managed flexible demand model is being implemented in ANM schemes, for example on the Shetland Islands, UK [20], [25] where domestic heating and industrial scale electrical heating are being combined with heat storage. The amount of energy to be delivered to a particular load is fixed across a day, but there is flexibility in when it is delivered. In this case it is the storage of heat that provides flexibility and will be described here as Storage Managed Flexible Demand (SMFD).

Direct Load Control mechanisms have been discussed in a number of papers (of which [26] gives an overview) and involves dictating scheduling of power delivery to an electricity load. In this paper, a Directly Managed Flexible Demand (DMFD) models this form of demand flexibility by allowing the ANM scheme to take direct control of a particular demand. For example, it may be a commercial process where the timing of when the process occurs is not critical.

\section{E. Voltage Control Techniques}

There can be significant variability in voltage levels across a distribution network and problems can be accentuated by the addition of DG. ANM communications can be used to coordinate the use of on load tap changing transformers and combine this with reactive power dispatch from DG and other devices. In general these techniques are 'time-independent'.

\section{F. Intertemporal ANM management and objectives}

The aim of ANM schemes are closely linked to the growth in renewable DG. ANM objectives are based around maximising the use of distributed renewable generation. With intertemporal devices, DOPF allows objectives to be maximized across an optimisation time-horizon rather than at each time-step individually. This can lead to a reduction in DG output during some time-steps if this maximizes the objective overall.

\section{A General Dynamic Optimal Power Flow FORMULATION}

The basis of a DOPF is the standard OPF formulation for the network. The generic formulation of an OPF and DOPF are shown in Table 1. In OPF a set of control variables are adjusted by the optimization process, fixed parameters define limits and parts of the system that cannot be adjusted, and derived variables are those which are functions of control variable and fixed parameters.

DOPF breaks the time-horizon up into $t_{n}$ time-steps and extends all OPF variables and some parameters into time series. The network must obey the typical OPF constraints such as power flow equations during each time-step independently. Furthermore, additional inter-temporal variables and constraints are created. An example of an inter-temporal variable is the State of Charge (SOC) of an ESS; that is the fraction of total energy capacity currently used. SOC depends on charge and discharge values in multiple time-steps. The DOPF objective is a function across all time-steps. 
TABLE 1: GENERAL FORMULATION FOR OPF AND DOPF

\begin{tabular}{|c|c|c|c|c|}
\hline & $\begin{array}{l}\text { Standard OPF } \\
\text { Formulation }\end{array}$ & OPF example & Dynamic OPF Formulation & DOPF example \\
\hline Control variables & $x$ & Power generated & $x(t)$ & $\begin{array}{l}\text { Power generated at generator bus varying } \\
\text { with time }\end{array}$ \\
\hline Fixed variables & $y$ & $\begin{array}{l}\text { Voltage magnitude at } \\
\text { voltage-controlled bus }\end{array}$ & $y(t)$ & $\begin{array}{l}\text { Voltage magnitude at voltage-controlled } \\
\text { bus varying with time }\end{array}$ \\
\hline Derivate variables & $\boldsymbol{Z}$ & Voltage angles & $z(t)$ & Voltage angles varying with time \\
\hline $\begin{array}{l}\text { Inter-temporal } \\
\text { variables }\end{array}$ & N/A & N/A & $\tau(t)$ & State of Charge (SOC) of storage device \\
\hline Objective function & $\min \boldsymbol{f}(\boldsymbol{x}, \boldsymbol{y}, \boldsymbol{z})$ & $\begin{array}{l}\text { Minimize cost of } \\
\text { operation }\end{array}$ & $\min f(\boldsymbol{x}(\boldsymbol{t}), \boldsymbol{y}(\boldsymbol{t}), \boldsymbol{z}(\boldsymbol{t}), \boldsymbol{\tau}(\boldsymbol{t}))$ & $\begin{array}{l}\text { Minimize overall cost across all time } \\
\text { periods. }\end{array}$ \\
\hline $\begin{array}{l}\text { Single time-step } \\
\text { equality constraints }\end{array}$ & $g(x, y, z)=0$ & Power flow equations & $g(x(t), y(t), z(t), \tau(t))=0 \forall t$ & $\begin{array}{l}\text { Power flow equations applied separately at } \\
\text { each time-step }\end{array}$ \\
\hline $\begin{array}{l}\text { Single time-step } \\
\text { inequality } \\
\text { constraints }\end{array}$ & $h(x, y, z) \leq 0$ & $\begin{array}{l}\text { Max / Min limits on } \\
\text { generator outputs and } \\
\text { bus voltages }\end{array}$ & $h(x(t), y(t), z(t), \tau(t)) \leq 0 \forall t$ & $\begin{array}{l}\text { Max / Min limits on generator outputs and } \\
\text { bus voltages. Max / Min values likely to } \\
\text { be the same during all periods }\end{array}$ \\
\hline $\begin{array}{l}\text { Inter-temporal } \\
\text { equality constraints }\end{array}$ & N/A & N/A & $k(x(t), y(t), z(t, \tau(t))=0 \forall t$ & $\begin{array}{l}\text { The total energy delivered to a load over } \\
\text { the optimization horizon should equal its } \\
\text { energy requirement }\end{array}$ \\
\hline $\begin{array}{l}\text { Inter-temporal } \\
\text { inequality } \\
\text { constraints }\end{array}$ & N/A & N/A & $l(x(t), y(t), z(t), \tau(t)) \leq 0 \forall t$ & $\begin{array}{l}\text { Max / Min limits on the SOC of a storage } \\
\text { device or Ramp rates on generators. }\end{array}$ \\
\hline
\end{tabular}

\section{DyNamic Optimal Power Flow For Active Network MANAGEMENT}

The development of a DOPF structure for ANM problems is based on a formulation of OPF suitable for use with distribution networks, and concentrates on the combination of firm and non-firm DG, energy storage and managed flexible demand. The inclusion of other ANM technologies, here called time-independent, are discussed in section VII. The variability of voltage across a DN caused by the high $\mathrm{R} / \mathrm{X}$ ratio and mainly radial layout means that a full AC OPF formulation is required.

The following scenario provides the structure for the scenario modelled within the DOPF:

- A distribution network containing both firm and non-firm generation. The network can have any number of Grid Connection Points linking it to the transmission network.

- Generic ESSs connected to specified busses.

- Managed flexible demand connected to specified busses.

- Objectives related to the utilization of renewable generation are modeled.

As the DOPF is a network-focused optimization, signconventions reflect this: ESS power injections are positive for discharging as they are modeled as generators.

\section{A. Objectives}

The objectives of the ANM scheme need to be converted into suitable mathematical formulations. Two are described here and further discussed in section VI.

1) Minimize distribution network imports / maximize exports

$$
f_{1}(\boldsymbol{x}(\boldsymbol{t}), \boldsymbol{y}(\boldsymbol{t}), \boldsymbol{z}(\boldsymbol{t}), \boldsymbol{\tau}(\boldsymbol{t}))=\min \sum_{t=1}^{t_{n}}\left\{\sum_{g c p=1}^{g c p_{n}} P_{g c p}(t)\right\}
$$

The optimization sums the imports to the network across each gcp and all time-steps in the optimization horizon. This objective aims to maximize the utilization of DG (rather than simply its generation) either through the ability of DG to meet local demand, or to export energy from the distribution network. Simply maximizing distributed generation raises the possibility that the optimal solution increases losses as a way of increasing generation, particularly when ESS losses are included.

\section{2) Minimize cost of import / maximize revenue from export:}

$$
\begin{array}{r}
f_{2}(\boldsymbol{x}(\boldsymbol{t}), \boldsymbol{y}(\boldsymbol{t}), \mathbf{z}(\boldsymbol{t}), \boldsymbol{\tau}(\boldsymbol{t})) \\
=\min \sum_{t=1}^{t_{n}} \pi(t)\left\{\sum_{g c p=1}^{g c p_{n}} P_{g c p}(t)\right\}
\end{array}
$$

This objective uses an exogenous electricity price and is of interest where the load and DG capacity on the distribution network is small compared with the overall electricity market. The objective is of particular interest where the DN or part of a $\mathrm{DN}$ is operating as an integrated entity such as a micro-grid.

\section{B. Standard OPF formulation}

Distribution network problems require a full ACformulation of the power flow equations, and as such OPF problems must be solved using non-linear programming methods such as gradient search or interior point methods. The formulation of the static OPF applied at each time-step as part of the DOPF is as follows:

- The power balance equations:

$$
\boldsymbol{g}(\boldsymbol{x}(\boldsymbol{t}), \boldsymbol{y}(\boldsymbol{t}), \boldsymbol{z}(\boldsymbol{t}), \boldsymbol{\tau}(\boldsymbol{t}))=\mathbf{0} \forall t
$$

These include constraints on nodal power balance and the power flow equations.

- Voltage levels at each bus:

$$
V_{\text {min }}(b)<V(b, t)<V_{\text {max }}(b) \forall b, t
$$

Where it is assumed that the maximum and minimum voltage limits remain fixed across the optimization horizon.

- Thermal line limits constrain the apparent power flow along each line: 


$$
-S_{\max }(l)<S(l, t)<S_{\max }(l) \forall l, t
$$

- Each gcp is modeled as a generator with the ability to supply positive and negative values of real and reactive power:

$$
\begin{gathered}
P_{g c p}^{\min }<P_{g c p}(t)<P_{g c p}^{\max } \forall g c p, t \\
Q_{g c p}^{\min }<Q_{g c p}(t)<Q_{g c p}^{\max } \forall g c p, t
\end{gathered}
$$

Busses connected to a $g c p$ operate as $P V$ buses (where real power and voltage are fixed parameters) and the primary gcp bus will act as the reference bus (where the voltage angle reference is defined).

\section{Firm distributed generation}

Firm generation is 'must-take' and is treated as negative fixed demand; the available generation from a firm generator is subtracted from the fixed bus demand. It is assumed that firm generators operate at fixed power factor and reactive power is also subtracted from bus demand.

\section{Non-Firm distributed generation}

Non-firm generation has a maximum output within each time-step, the value of $P_{g}^{\max }(n f, t)$ for each time-step is defined by the available wind resource:

$$
0<P_{g}(n f, t)<P_{g}^{\max }(n f, t) \quad \forall n f, t
$$

The power of non-firm generators is a control variable and can be scheduled anywhere within its range.

\section{E. Principles of Access for non-firm generation}

Modeling the PoA for non-firm generators in a DOPF can be achieved by modifying the objective function or adding additional constraints as set out below.

1) Priority order (e.g. LIFO)

For the DOPF to apply a priority order, there must be a distinction in the value of generation from different generators. This is accomplished by modifying the objective function.

For the objective of minimize import, (1), can be modified to include a second term defining the priority order:

$$
\begin{aligned}
& f_{1}(\boldsymbol{x}(\boldsymbol{t}), \boldsymbol{y}(\boldsymbol{t}), \boldsymbol{z}(\boldsymbol{t}), \boldsymbol{\tau}(\boldsymbol{t}))= \\
& \min \sum_{t=1}^{t_{n}}\left\{\sum_{g c p=1}^{g c p_{n}} P_{g c p}(t)+\sum_{n f=1}^{n f_{n}} \frac{p}{k} P_{g}(n f, t)\right\}
\end{aligned}
$$

where $p$ is an integer between 1 and $n_{n f}$ with high numbers representing low priority generators, the definition of the

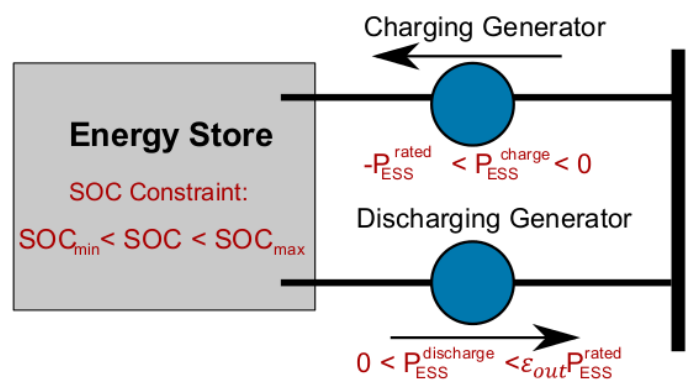

Fig. 1. Two generator model of an ESS

constant $k$ is discussed below.
The original objective has now been adjusted so that generation from high priority generators have more value than for low priority generators in minimizing the objective, but this 'priority order' value should be small so that the first term in (1a) dominates. This ensures that the optimization continues to minimize imports whilst the small adjustment of the second term provides the priority and chooses which DG to dispatch. This effect is achieved by choosing $k$ so that $k^{-1} \ll 1$ and $p / k<1$ for the lowest priority generator (highest $p$ ). It is also important that $k^{-1}$ is large enough that the priority term is larger than the tolerance value used by the DOPF algorithm to define convergence.

Applying priority orders to objective 2, defined in (2), can be achieved in a similar way, and the second term from (1a) can be added to (2) to create the required objective. In this case the requirement on $k$ is that $p / k<\min (\boldsymbol{\pi}(t))$ for the lowest priority generator.

\section{2) Shared percentage}

A shared percentage scheme is one in which all generators receive the same percentage net overall curtailment across the time-horizon of the optimization. This can be modeled through additional constraints on the non-firm generation control variables:

$$
\sum_{t=1}^{t_{n}} \frac{P_{g}\left(n f_{i}, t\right)}{P_{g}^{\max }\left(n f_{i}, t\right)}=\sum_{t=1}^{t_{n}} \frac{P_{g}\left(n f_{j}, t\right)}{P_{g}^{\max }\left(n f_{j}, t\right)} \forall i \neq j
$$

where $i$ and $j$ refer to different non-firm generators. Here the fractional energy curtailed at each wind farm must be the same across the optimization-horizon. Shared percentage provides flexibility regarding which generators can be curtailed when. It will be useful when carrying out planning studies over timehorizons of months rather than for day-ahead scheduling.

\section{3) Technical best}

Technical best PoA means dispatching the generator that best helps the network meet its objective. In the DOPF formulation this will be achieved by using the original objective and allowing the DOPF to choose which generator to curtail.

\section{F. Energy Storage Systems}

The role of power lines in an OPF is to link network nodes which are spatially separated. In DOPF, ESS can be thought of as carrying out a similar role linking nodes that are separated in time rather than space. Both power lines and ESSs act as vectors transferring energy around the network.

ESS systems can be modeled as generators with the ability to inject positive or negative power onto the network and a SOC variable to keep track of the stored energy. The relationship between the power injections in each period and the SOC of the store includes a discontinuity:

$$
\Delta S O C=-\frac{\Delta t}{E_{E S S}^{\text {cap }}} \begin{cases}\varepsilon_{\text {in }} P_{E S S} & \text { if } P_{E S S} \geq 0 \\ \frac{1}{\varepsilon_{\text {out }}} P_{E S S} & \text { if } P_{E S S}<0\end{cases}
$$

$P_{E S S}$ is positive when discharging and negative when charging, and refers to the flow of power as seen by the grid. The efficiency factors relate this value to the power injected or removed from the ESS including conversion losses. The roundtrip efficiency of the store is the product of $\varepsilon_{\text {in }}$ and $\varepsilon_{\text {out }}$. The 
discontinuity of (9) cannot be directly accommodated in a nonlinear programming solution.

This discontinuity can be removed by modeling the ESS with separate generators for charging and discharging so that:

$$
P_{E S S}=P_{E S S}^{\text {dis }}+P_{E S S}^{\text {charge }}
$$

with the charging generator operating with negative values. Fig. 1. shows this conception of the ESS model. The real-power generation of the two generators is constrained as follows:

$$
\left.\begin{array}{c}
-P_{E S S}^{\text {rated }}(t)<P_{E S S}^{\text {charge }}(t)<0 \\
0<P_{E S S}^{\text {dis }}(t)<\varepsilon_{\text {out }} P_{E S S}^{\text {rated }}(t)
\end{array}\right\} \forall t
$$

where $P_{E S S}^{\text {charge }}$ is the power of the 'charging generator' and is negative relative to the grid, and $P_{E S S}^{\text {discharge }}$ is the discharging generator.

The SOC is now related to the power flows of two generators, and for each period is defined by:

$$
\begin{aligned}
& S O C_{E S S}(t)=S O C_{E S S}(0) \\
& -\frac{\varepsilon_{\text {in }} \Delta t}{E_{E S S}^{\text {cap }}} \sum_{t^{\prime}=1}^{t} P_{E S S}^{\text {charge }}\left(t^{\prime}\right) \\
& -\frac{\Delta t}{E_{E S S}^{\text {cap }} \varepsilon_{\text {out }}} \sum_{t^{\prime}=1}^{t} P_{E S S}^{\text {dis }}\left(t^{\prime}\right)
\end{aligned}
$$

where $\operatorname{SOC}(0)$ is the initial SOC. The SOC is constrained to remain within limits:

$$
S O C_{E S S}^{\min }<S O C_{E S S}(t)<S O C_{E S S}^{\max } \forall t
$$

These limits may be 0 and 1 , however it is likely that some operational strategies will want to avoid charging and discharging an ESS to its theoretical limits. In general it is expected that the initial, $t_{0}$, and final, $t_{n}$, SOC are the same:

$$
S O C_{E S S}\left(t_{0}\right)=S O C_{E S S}\left(t_{n}\right)
$$

This formulation provides a significant improvement over existing techniques. For example in [11] charging and discharging time-steps are pre-defined as inputs to the formulations, in [12] the formulation does not predefine charging discharging time-steps but at the expense of a full formation of efficiency.

Note that in this formulation there is no constraint to stop charging and discharging generators operating during the same time-step. It is therefore a mathematically feasible solution to charge and discharge during the same time-step although obviously not physically realizable in an ESS. Such a solution, whilst feasible in this framework can be seen to be non-optimal if: (i) the round-trip efficiency of the ESS is less than 1 and (ii) the 'cost' of all generation in the objective is positive. The situation is therefore avoided in the optimal solution.

To demonstrate this, consider the physical system. During a particular time-step there is an optimal change in SOC, $\triangle S O C$, relating to a charge or discharge of the ESS. In the mathematical formulation this can be achieved by a combination of charging and discharging that obeys:

$$
\Delta S O C=\frac{-\Delta t}{E_{E S S}^{\text {cap }}}\left\{\varepsilon_{\text {in }} P_{E S S}^{\text {charge }}+\frac{P_{E S S}^{\text {dis }}}{\varepsilon_{\text {out }}}\right\}
$$

where $P_{E S S}^{\text {charge }}$ represents power that must be generated elsewhere (either by DG or imported via a $g c p$ ). If the cost of generating this power is positive in the objective function then minimizing the objective includes minimizing the value of $\left|P_{E S S}^{\text {charge }}(t)\right|$ for the optimal $\triangle S O C$. If $\varepsilon_{\text {in }} \varepsilon_{\text {out }}<1$ this minimum occurs when $P_{E S S}^{\text {charge }}(t)=0$ for charging periods and $P_{E S S}^{\text {dis }}(t)=0$ for discharging periods. Thus, for a positive cost of generation and an ESS efficiency less than 1, an optimal solution will only operate at most one of the two charging/discharging generators during each period.

In addition to the real power constraints described in (11), the ESS unit is able to provide reactive power support. The combination of real and reactive power from an ESS is limited by the apparent power according to:

$$
S_{E S S}(t)<S_{E S S}^{\text {rated }}(t)
$$

where:

$$
S_{E S S}(t)=\sqrt{P_{E S S}^{2}+Q_{E S S}^{2}}
$$

\section{G. Managed Flexible Demand}

A flexible demand unit is modeled as a generator with negative output where the output magnitude during each timestep is a control variable. The two models proposed in section II are now described.

1) Directly managed flexible demand (DMFD)

The total energy delivered to the load across the timehorizon must be equal to the energy requirement. This is simply:

$$
\Delta t \sum_{t=1}^{t_{n}} P_{D M F D}(t)=E_{D M F D}
$$

For each time-step, the power delivered is bound by the rated capacity of the load and a minimum power delivery for that time-step, the value of $P_{D M F D}^{\min }(t)$ may be 0 for all $t$ or may be higher to allow for some consumer preference regarding minimum power delivery at predefined times:

$$
-P_{D M F D}^{\text {rated }}<P_{D M F D}(t)<-P_{D M F D}^{\min }(t)
$$

\section{2) Storage Managed Flexible Demand (SMFD)}

If a form of storage such as a heat store is used to provide flexibility, (18) and (19) should be augmented with equations to define and manage the SOC on that heat store. It is assumed that a fixed demand schedule for energy delivery (e.g. $\left.P_{\text {Heat }}(t)\right)$ is buffered by the heat storage:

$$
\begin{gathered}
S O C_{S M F D}(t)=S O C_{S M F D}(0)-\frac{\Delta t \mu}{E_{S M F D}^{\text {cap }}} \sum_{t^{\prime}=1}^{t} P_{S M F D}^{\text {charge }}\left(t^{\prime}\right) \\
-\frac{\Delta t}{E_{S M F D}^{\text {cap }}} \sum_{t^{\prime}=1}^{t} P_{\text {Heat }}\left(t^{\prime}\right)
\end{gathered}
$$


Note that as $P_{\text {Heat }}$ is not related to the electrical network it is defined as positive for demand; $\mu$ is the efficiency of conversion between electrical and stored energy (known as the Coefficient of Performance), and for heat-pump technologies this may be greater than 1 [27]. $P_{S M F D}(t)$ is modeled as a generator with negative power flows. SOC constraints are the same as those for ESS:

$$
\begin{gathered}
S O C_{S M F D}^{\min }<S O C_{S M F D}(t)<S O C_{S M F D}^{\max } \forall t \\
\operatorname{SOC}_{S M F D}(0)=S O C_{S M F D}\left(t_{n}\right)
\end{gathered}
$$

and the rate of charge is constrained by:

$$
-P_{S M F D}^{\text {rated }}(t)<P_{S M F D}(t)<-P_{S M F D}^{\min }(t)
$$

\section{CASE STUdy}

This section presents a case study of a distribution network operating an ANM scheme with inter-temporal components. The DOPF formulated using (1) - (23) is illustrated on a radial network with some meshing typical of a rural distribution network. It is based on the UK Generic Distribution System simplified rural Extra High Voltage network, and an outline of the network is shown in Fig. 2 [28].

DG and ANM components are added to the network as shown in Fig. 2, while the parameters used are listed in Table 2, and time-series for demand and generation are shown in Fig. 3. For simplicity all DG is modeled as wind generation with the same wind profile. The optimization is for a 24-hour horizon split up into 15-minute time-steps. Fixed demand at each bus and available generation at each wind farm is the product of total capacity and the relevant normalized time series. As DG penetration is high, the objectives from section IV part A are referred to as 'maximizing export' and 'maximize revenue'.

The following scenarios are used to illustrate the effectiveness of the DOPF model and summarized in Table 2:

1) Firm and Non-firm wind only, maximize export objective, priority-order PoA with a value of $k=0.01$ in (1a). No other ANM devices are added.

2) As for scenario $1+$ ESS.

3) As for scenario $2+$ DMFD and SMFD. Flexible demand replaces fixed demand so that total energy demand is the same as for scenarios 1 and 2 .

4) As for scenario 3 using the maximize revenue objective.

\section{A. Implementation}

The DOPF has been implemented in conjunction with the MATPOWER suite for power system analysis [29]. The extensible architecture of the software allows for easy customization of standard OPF problems. MATPOWER's own Interior Point Algorithm (MIPS) is used as the solver. On a quad-core $3 \mathrm{GHz}$ desktop the optimization solves in approximately 3.5 seconds.

\section{B. Results}

Results for curtailment, exported energy, and losses are shown in Table 3 which also shows revenue from export in scenarios 3 and 4 .

The results show that when the system is operated as a curtailment scheme only (i.e. without ESS or flexible demand)

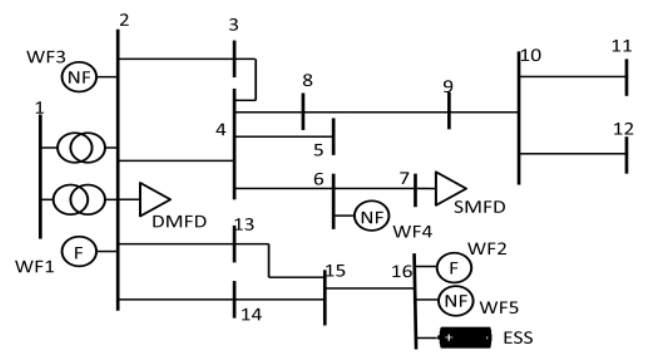

Fig. 2. Case study distribution network. All generators represent wind farms and additional ANM devices are shown connected.

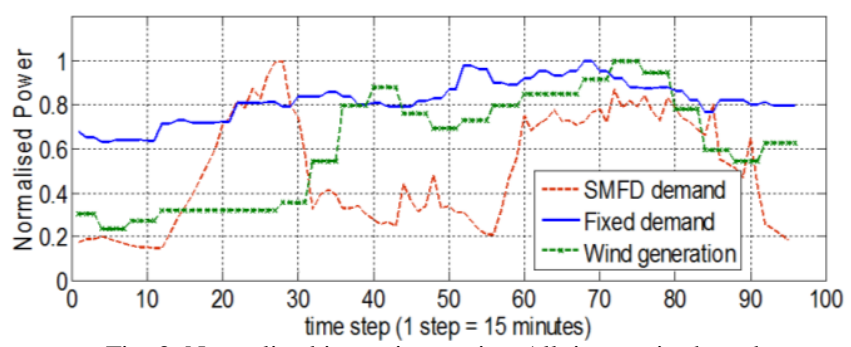

Fig. 3. Normalized input time-series. All time-series have been normalized against their maximum value.

\begin{tabular}{|c|c|c|c|c|c|}
\hline Component & \multicolumn{4}{|c|}{ Scenario } & Variables \\
\hline & 1 & 2 & 3 & 4 & \\
\hline Time steps & $\checkmark$ & $\checkmark$ & $\checkmark$ & $\checkmark$ & $t_{n}=96 ; \Delta t=0.25$ hours \\
\hline WF1 (Firm) & $\checkmark$ & $\checkmark$ & $\checkmark$ & $\checkmark$ & $P_{g}^{\text {Capacity }}=40 M W$ \\
\hline WF2 (Firm) & $\checkmark$ & $\checkmark$ & $\checkmark$ & $\checkmark$ & $P_{g}^{\text {Capacity }}=9 M W$ \\
\hline WF3 (NF) & $\checkmark$ & $\checkmark$ & $\checkmark$ & $\checkmark$ & $P_{g}^{\text {Capacity }}=30 M W ; p=1$ \\
\hline WF4 (NF) & $\checkmark$ & $\checkmark$ & $\checkmark$ & $\checkmark$ & $P_{g}^{\text {Capacity }}=25 M W ; p=2$ \\
\hline WF5 (NF) & $\checkmark$ & $\checkmark$ & $\checkmark$ & $\checkmark$ & $P_{g}^{\text {Capacity }}=20 M W ; p=3$ \\
\hline ESS & & $\checkmark$ & $\checkmark$ & $\checkmark$ & $\begin{array}{c}S O C_{\max }=18 \mathrm{MWh} \\
P_{\max }^{\text {charge }}=P_{\max }^{\text {discahrge }}=3 \mathrm{MW} \\
S O C_{0}=S O C_{\text {final }}=9 \mathrm{MWh}\end{array}$ \\
\hline DMFD & & & $\checkmark$ & $\checkmark$ & $\begin{aligned} E_{\text {required }} & =106 \mathrm{MWh} \\
P_{\max } & =6 \mathrm{MW}\end{aligned}$ \\
\hline SMFD & & & $\checkmark$ & $\checkmark$ & $\begin{array}{c}S O C_{\max }=10 \mathrm{MWh} ; \\
P_{\max }^{\text {charge }}=2 \mathrm{MW} \\
S O C_{0}=S O C_{\text {final }}=5 \mathrm{MW} \\
E_{\text {required }}=37 \mathrm{MWh} ; \mu=1\end{array}$ \\
\hline
\end{tabular}

TABLE 2 : PARAMETERS OF DISTRIBUTED GENERATION AND ANM COMPONENTS.

$18 \%$ of the available non-firm generation is curtailed across the whole day. This curtailment is distributed in line with the priority order, with the highest priority wind farm receiving no curtailment and the lowest priority generator receiving the most, at $55 \%$ of output. The time-series of curtailment for WF 4 and WF5 is shown in Fig. 4. WF5 is fully curtailed during 16 time-steps and at these times WF4 is partially curtailed. There are 25 time-steps (out of 96) when WF4 is not curtailed and WF5 is partially curtailed. There are also 24 time-steps where both WF4 and WF5 are partially curtailed. At these times local thermal constraints on the line between bus 4 and bus 6 limit the output from WF4 without affecting that from WF5. 
In scenario 2, the addition of ESS increases the energy exported by $12 \mathrm{MWh}(1.3 \%)$ and reduces curtailment by $16 \mathrm{MWh}(1.5 \%)$. The operating schedule for the ESS device is shown in Fig. 5. and the SOC schedule in Fig. 6. The curtailment is decreased by more than the export rises as overall losses rise by $4 \mathrm{MWh}$. Whilst the export increase is relatively small compared with total export, a more useful comparison is with the maximum energy that such an ESS can time-shift in a 24 hour period. A $3 \mathrm{MW}, 18 \mathrm{MWh}$ unit can in total time-shift $36 \mathrm{MWh}$ in a day, so a value of $12 \mathrm{MWh}$ equates to $33 \%$ of this value. From Fig 8. it is seen that the SOC reaches its minimum level, therefore maximizing the utilization within a single charge-cycle. Given the distribution of curtailment throughout the day, greater utilization could be achieved if the initial and final SOC were greater than 0.5. The ESS device is located at the same bus as WF5 and is able to directly manage congestion on the line linking it to the rest of the network. However, during periods where WF4 is constrained due to congestion in exporting from the network (between busses 1 and 2) rather than due to its local congestion, the ESS device is able to reduce the curtailment of WF4 as well. In addition, the ESS is able to use its reactive capabilities to manage the reactive power and voltage levels. For example, during time-steps 52 - 54 Fig. 5. shows that the increase in wind generation is greater than the power demand by the ESS. Due to the high penetration of DG at bus 16, the maximum voltage level of $1.06 \mathrm{pu}$ is a constraining factor, leading to curtailment of WF5. By regulating reactive power, the ESS is able to allow additional generation at that bus.

The replacement of fixed demand with flexible demand in scenario 3 leads to a further reduction in curtailment and a rise in export. The flexible demand is scheduled by DOPF for timesteps where it reduces curtailment. Fig. 7 shows the schedule for the SMFD at bus 7 and the curtailment experience by WF4 with and without flexible demand: the demand has been moved to coincide with periods of curtailment and leads to a reduction in that curtailment. The DMFD at bus 2 is not local to either of
TABLE 3 : CURTAILMENT AT NF WIND FARMS IN EACH OF THE SCENARIOS MODELLED

\begin{tabular}{|c|c|c|c|c|c|c|c|c|}
\hline Scenario & \multicolumn{2}{|c|}{1} & \multicolumn{2}{|c|}{2} & \multicolumn{2}{|c|}{3} & \multicolumn{2}{|c|}{$\overline{4}$} \\
\hline $\begin{array}{l}\text { Curtail- } \\
\text { ment }\end{array}$ & $M W h$ & $\%$ & $M W h$ & $\%$ & $M W h$ & $\%$ & $M W h$ & $\%$ \\
\hline WF3 & 0 & 0 & 0 & 0 & 0 & 0 & 0 & 0 \\
\hline WF4 & 59.2 & 16.0 & 51.2 & 12.9 & 41.6 & 11.2 & 43.9 & 11.8 \\
\hline WF5 & 163 & 54.9 & 155 & 49.5 & 147 & 49.5 & 145 & 48.9 \\
\hline Total: & 222 & 17.6 & 206 & 16.1 & 189 & 15.0 & 189 & 15.0 \\
\hline $\begin{array}{l}\text { Export } \\
(M W h) \text { : }\end{array}$ & 960 & & 972 & & 988 & & 987 & \\
\hline $\begin{array}{l}\text { Revenue } \\
(£ 10,000)\end{array}$ & & $\bar{A}$ & & $A$ & & 96) & & 06 \\
\hline $\begin{array}{l}\text { Losses } \\
(M W h)\end{array}$ & & .2 & & .3 & & & & .6 \\
\hline
\end{tabular}

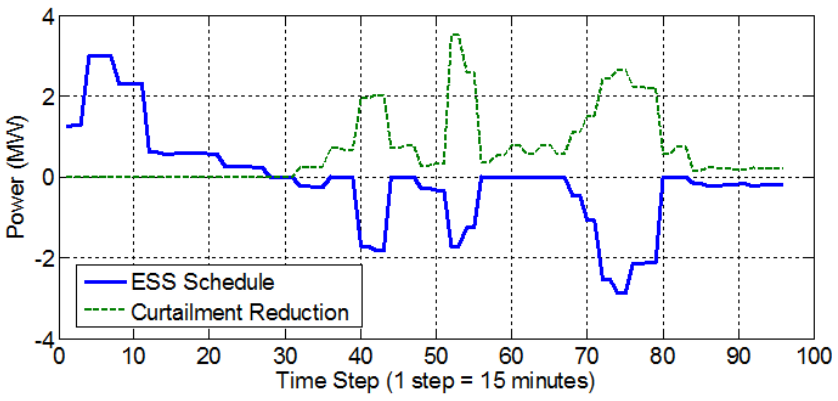

Figure 5: ESS schedule for scenario 2

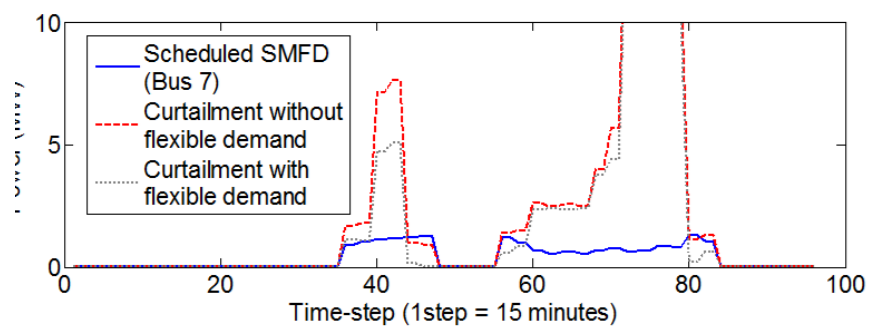

Fig. 7. Scheduling of SMFD at bus 8 compared with curtailment at WF4 with and without flexible demand

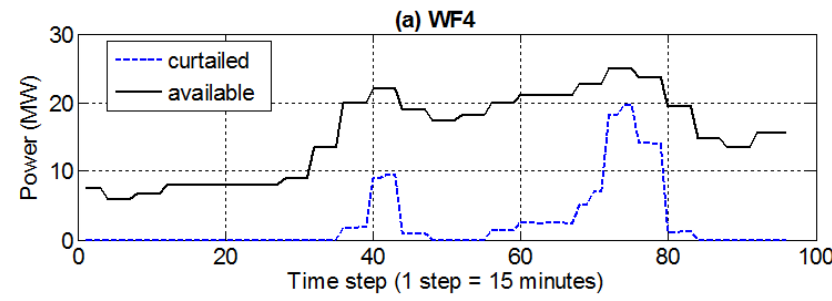

(b) WF5

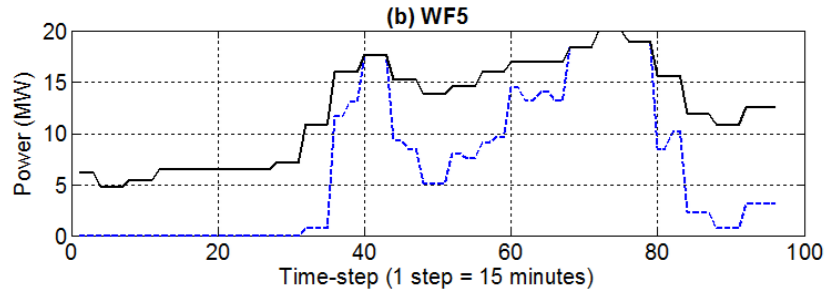

Fig. 4. Curtailment of WF4 and 5 in scenario 1.

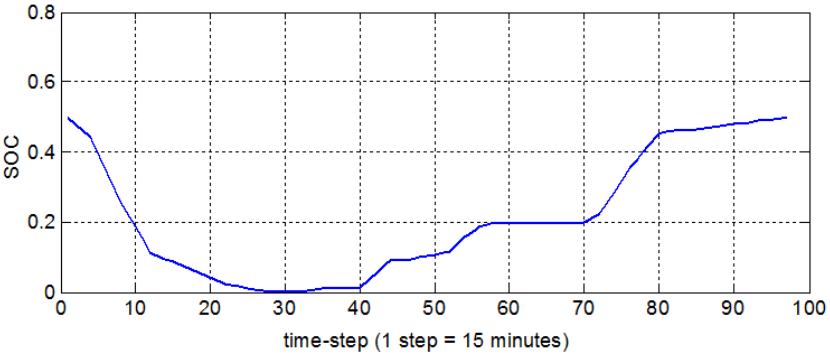

Figure 6: SOC of the ESS in scenario 2

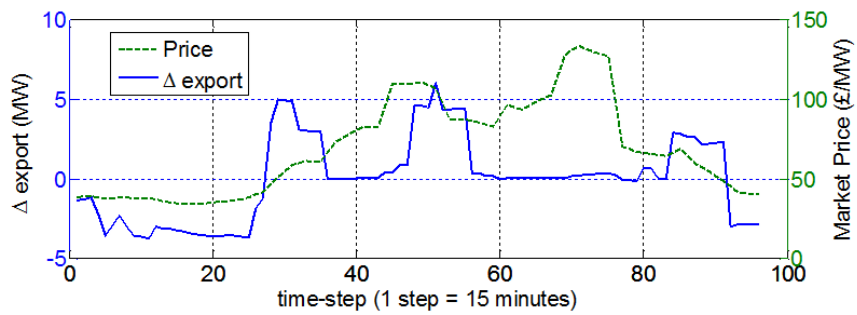

Fig. 8. Change in export between scenario 3 (Maximize export) and scenario 4 (Maximize revenue), positive value represent greater export under maximize revenue. 
the wind farms but by managing congestion on the export constraint it further reduces curtailment at both WF4 and WF5.

The network setup for scenario 4 is the same as that for 3 , with the objective changed to reflect the external market price for energy. The change in objective leads to a number of changes in the optimal solution: firstly the total energy export is very slightly smaller, but there is a change in the timing of export to coincide with periods of high market price. When compared to the revenue that would be raised by the results for the previous scenario there is a rise of $1.3 \%$ in revenue. Fig. 8 shows the change in export between the two scenarios and the market price. When the export is not constrained the "maximize revenue' objective leads to reduced export when price is low and increased export when price is high. Time-steps with nochange between the scenarios are those where the export link is at full capacity.

\section{DISCUSSION}

The case study illustrates that the DOPF structure presented can be successful in producing optimal dispatches for ESS and flexible demand in an ANM context. It is able to use the flexibility to raise export by $2.9 \%$ compared with simple curtailment.

The case study presented models ANM examples which are now being rolled out to real-world distribution networks. This includes the extension of the Orkney smart grid to include energy storage [18], and the use of SMFD on the Shetland Distribution network [20]. As such schemes develop and the penetration of these enabling technologies increases, so too will the ability to manage curtailment. DOPF provides a tool for investigating the effect of the sizes and location of ESS units. Table 4 gives examples of the total export increase (compared with scenario 1) if the location and size of the ESS in scenario 2 is varied. For a similar sized ESS unit, locating it at bus 2 rather than bus 16 leads to greater increases in exported energy as it is able to more effectively utilize curtailment from more $\mathrm{NF}$ wind farms. But in both locations, the continued increase in ESS capacity leads to diminishing returns in terms of increased export. This is because on the margin there is less curtailment to remove and the network capacity is more fully utilized. The optimal levels of ESS at each bus will be a function of economic factors as well as technical factors. A key area of future research utilizing DOPF based tools will be to investigate the trade-offs between size, costs, location and the ownership models used for distributed ESS.

TABLE 4: EXPORT INCREASE RELATIVE TO SCENARIO 1 FOR VARIATIONS IN SIZE AND LOCATION OF ESS

\begin{tabular}{l|c|c|c}
\hline Location & $\begin{array}{c}\text { Size } \\
(\mathrm{MW} / \mathrm{MWh})\end{array}$ & $\begin{array}{c}\text { Export Increase } \\
(\mathrm{MWh})\end{array}$ & $\begin{array}{c}\text { Export increase per } \\
\text { MW of ESS (MW) }\end{array}$ \\
\hline 16 & $3 / 18$ & 12.8 & 4.3 \\
\hline 16 & $15 / 90$ & 42.8 & 2.9 \\
\hline 16 & $30 / 180$ & 48.2 & 1.6 \\
\hline 2 & $3 / 18$ & 19.2 & 6.4 \\
\hline 2 & $15 / 90$ & 49.0 & 3.2 \\
\hline 2 & $30 / 180$ & 51.3 & 1.7 \\
\hline
\end{tabular}

Similar analysis can be carried out with flexible demand, however these technologies raise a number of other issues related to the behavior of consumers. The models presented here assume that consumer demand can be predicted accurately in advance, and that those consumers are willing to give up their ability to control the load. The likelihood of these assumptions being true depends on the type of load being controlled. One example is the load recovery period where demand spikes above the average at the end of a period where the delivery of energy to a load has been restricted [30]. DOPF is able to model these type of effects, for example, by defining the energy to be delivered during each three hour block of the day or limiting load controllability to particular parts of the day. The results presented here show that within the DOPF model simple optimal load-scheduling can be combined with ESS and curtailment schemes in a format that is flexible enough to consider more complex schemes in future work.

The usefulness of this model in the operational context is that it can be run using forecasts of generation and demand to provide the optimal solution for the forecast conditions; creating effective schedules based on day-ahead forecasts is a requirement of the Shetland ANM [20]. Retrospectively it can be used with historic measurements of demand and generation to benchmark the success of the actual schedules used. The short time required to solve the DOPF ( 3.5 seconds) also allows the method to be combined with probabilistic techniques such as Monte Carlo simulation. For example the case study used can be solved for approximately 1,200 demand and generation cases within 1 hour on a standard desktop.

The methodology presented here can be applied to larger and more complex networks, with operational speed being the limiting factor. When a larger network consisting of 68 busses and representing an existing distribution network, the solution time is approximately 7 seconds.

Whilst this case study concentrated on the inter-temporal aspects, other ANM technologies that are time-independent can easily be incorporated. There are OPF formulations in the literature to deal with coordinated voltage control, power-factor control from DG, and ANM power flow management [31]-[33]. Including these in the DOPF formulation simply involves extending the variables and constraints used in the original work to time-series variables and applying them independently at each time-step.

There are a range of objectives that the DOPF formulation can be used for. The two illustrated here concentrate on the effect of DG and ANM on the overall aim rather than on the DG itself: maximizing exported energy or revenue is the objective rather than simply maximizing the output by DG. It is likely that a feasible dispatch of ESS and FD exists with curtailment lower than the 189MWh achieved in Scenarios 3 and 4 but with higher losses; it is important that the use of DG is considered in the objective. The importance of losses in systems with high penetration of renewable generation needs careful consideration when developing objectives for DOPF. OPF analysis of networks with mainly conventional generation often uses the objective of minimizing losses. When renewable curtailment is involved, both losses (network or ESS) and curtailment are similar in that they represent the non-use of renewable energy. It is important that the objective function represents the real aims of the ANM scheme. 
The use of priority-order PoA is one that has so far been favored due to its simplicity and transparency to wind farm developers. But others may be more effective at encouraging the development of DG within ANM schemes. In scenario 3, the level of curtailment varies significantly across the non-firm portfolio with WF3 receiving zero curtailment and WF5 almost $50 \%$. It is very likely that if this is indicative of a normal day that WF5 will be uneconomical. That value of $50 \%$ should be contrasted with that of $15 \%$ curtailment across the entire nonfirm portfolio. In the UK, the average capacity factor of wind farms was 27\% during 2011 [34]. Using this as an estimate for 'viable' development, a wind farm that is curtailed for $50 \%$ of the time would require an available capacity factor of 54\%. If curtailment were $15 \%$ the un-curtailed wind farm capacity factor would need to be $32 \%$ for it to be viable after curtailment. Finding sites with the wind resource required for a wind farm with $32 \%$ capacity factor is feasible, especially in areas of high resource, such as those where current ANM development is happening. The DOPF structure can be used to inform PoA development.

\section{CONCLUSION}

This paper presents a general Dynamic Optimal Power Flow framework for use with Active Network Management schemes. ANM technologies are presented with a focus on inter-temporal effects. The DOPF is developed specifically to model curtailment of renewable distributed generation, energy storage systems and flexible demand. A case-study network and ANM scheme is solved to illustrate the effectiveness of the framework in scheduling for realistic time-horizons such as one day. Under an objective of maximizing total energy exported the framework optimizes energy storage and flexible demand to raise export by $2.9 \%$, whilst in the process reducing curtailment of non-firm generation by $14 \%$. Finally the extension of DOPF to include other ANM relevant technologies including existing OPF formulation for time-independent technologies is discussed.

\section{REFERENCES}

[1] H. W. Dommel and W. F. Tinney, "Optimal Power Flow Solutions," Power Apparatus and Systems, IEEE Transactions on, vol. PAS-87, pp. 1866-1876, 1968

[2] J. H. Talaq, F. El-Hawary, and M. E. El-Hawary, "Minimum emissions power flow," Power Systems, IEEE Transactions on, vol. 9, pp. 429435, 1994.

[3] G. P. Harrison and A. R. Wallace, "Maximising distributed generation capacity in deregulated markets," in Transmission and Distribution Conference and Exposition, 2003 IEEE PES, 2003, pp. 527-530 vol.2.

[4] G. P. Harrison and A. R. Wallace, "Optimal power flow evaluation of distribution network capacity for the connection of distributed generation," Generation, Transmission and Distribution, IEE Proceedings-, vol. 152, pp. 115-122, 2005.

[5] F. Milano, Power System Modelling and Scripting, first edition. London: Springer, 2010.

[6] K. Lee and M. El-Sharkawi, Modern Heuristic Optimization Techniques. Theory and applications to power systems, First Edition ed. Hokoken: John Wiley \& Sons, 2008.

[7] M. E. El-Hawary and D. H. Tsang, "The Hydrothermal Optimal Load Flow, A Practical Formulation and Solution Techniques Using Newton's Approach," Power Systems, IEEE Transactions on, vol. 1, pp. 157-166, 1986.

[8] W. Hau, H. Sasaki, J. Kubokawa, and R. Yokoyama, "Large scale hydrothermal optimal power flow problems based on interior point nonlinear programming," Power Systems, IEEE Transactions on, vol. 15, pp. 396-403, 2000.

[9] W. Uturbey and A. S. Costa, "Interruptible load management assessment via dynamic optimal power flow," in Power Tech Conference Proceedings, 2003 IEEE Bologna, 2003, p. 7 pp. Vol.4.

[10] A. L. Costa and A. S. Costa, "Energy and ancillary service dispatch through dynamic optimal power flow," Electric Power Systems Research, vol. 77, pp. 1047-1055, 2007.

[11] Gabash, A., Li P., 2012, Active-Reactive Optimal Power Flow in Distribution Networks With Embedded Generation and Battery Storage, IEEE Transactions on Power Systems, Volume: 27 , Issue 4, Page(s): $2026-2035$

[12] A. J. Lamadrid, T. D. Mount, and R. J. Thomas, "Scheduling of Energy Storage Systems with Geographically Distributed Renewables," in Parallel and Distributed Processing with Applications Workshops (ISPAW), 2011 Ninth IEEE International Symposium on, 2011, pp. 8590.

[13] V. Stanojevic, V. Silva, D. Pudjianto, G. Strbac, P. Lang and D. McLehman, "Application of Storage and Demand Side Management to Support the Integration of Intermittent Distributed Generation", in Proc. of CIRED, Prague, 2009;

[14] DTI, "A Technical Review and Assessment of Active Network Management Infrastructures and practices," London 2006.

[15] S. K. Merz, "Active Network Management (ANM) Technology. Current Issues and Identification of Technical Opertunities for Active Network Management," BERR2008.

[16] N. Jenkins, R. Allan, P. Crossley, D. Kirschen, and G. Strbac, Embedded Generation. London: IEE, 2000.

[17] SSE, "Facilitate Generation Connections on Orkney by Automatic Distribution Network Management," Department of Trade and Industry 2004.

[18] SSE. (2012, 22/08/2012). Orkney Smart Grid. Available: http://www.ssepd.co.uk/OrkneySmartGrid/

[19] A. Nourai, "Installation of the First Distributed Energy Storage System (DESS) at American Electric Power (AEP)," Department of Energy, Albuquerque2007.

[20] M. J. Dolan, G. W. Ault, D. F. Frame, S. Gill, I. Kockar, O. AnayaLara, S. Galloway, B. O’Neill, C. Foote, A. Svalovs, and K. Jackson, "Northern Isles New Energy Solutions: Active Network Management Stability Limits," presented at the ISGT Europe, Berlin, 2012.

[21] R. MacDonald, R. Currie, G. Ault, and J. Douglas, "Register of Active Management Pilots, Trials, Research, Development and Demonstration Activities," Available at: http://www.ensg.gov.uk/index.php?article=952008.

[22] R. Currie, B. Neill, C. Foote, A. Gooding, R. Ferris, and J. Douglas, "Commercial arrangements to facilitate active network management," presented at the CIRED, Frankfurt, 2011.

[23] M. Beaudin, H. Zareipour, A. Schellenberglabe, and W. Rosehart, "Energy storage for mitigating the variability of renewable electricity sources: An updated review," Energy for Sustainable Development, vol. 14, pp. 302-314, 2010.

[24] Walker, L.H.; , "10-MW GTO converter for battery peaking service," Industry Applications, IEEE Transactions on , vol.26, no.1, pp.63-72, Jan/Feb 1990

[25] S. Gill, M. J. Dolan, D. Frame, and G. Ault, "The Role of the Electric Heating and District Heating Networks in the Integration of Wind Energy to Island Networks," International Journal of Distributed Energy Resources, vol. 7, pp. 245-262, July 20112011.

[26] Callaway, D.S., Hiskens, I.A., "Achieving Controllability of Electric Loads," Proceedings of the IEEE, vol.99, no.1, pp.184-199, Jan. 2011

[27] K.J. Chua, S.K.Chou, W.M.Yang, "Advances in heat pump systems: A review, "Applied Energy, vol. 87, pp. 3611 - 3624, December 2010

[28] SEDG. (2004), Centre for Sustainable and Distributed Generation website. Available: http://www.sedg.ac.uk/

[29] R. D. Zimmerman, C.E. Murill-Sanchez, and R. J. Thomas, "MATPOWER: Steady-State Operations, Planning, and Analysis Tools for Power Systems Research and Education," Power Systems, IEEE Transactions on, vol. 26, pp. 12-19, 2011.

[30] V. Silva, V. Stanojevic, M. Aunedi, D. Pudjianto and G. Strbac, Smart domestic appliances as enabling technology for demand side integration: modeling, value and drivers", ed. M. Pollit, Cambridge University Press, Cambridge, 2011 
[31] S. N. Liew and G. Strbac, "Maximising penetration of wind generation in existing distribution networks," Generation, Transmission and Distribution, IEE Proceedings-, vol. 149, pp. 256-262, 2002.

[32] L. F. Ochoa, C. J. Dent, and G. P. Harrison, "Distribution Network Capacity Assessment: Variable DG and Active Networks," Power Systems, IEEE Transactions on, vol. 25, pp. 87-95, 2010.

[33] M. J. Dolan, E. M. Davidson, I. Kockar, G. W. Ault, and S. D. J. McArthur, "Distribution Power Flow Management Utilizing an Online Optimal Power Flow Technique," Power Systems, IEEE Transactions on, vol. 27, pp. 790-799, 2012

[34] DECC (2012, 26th September 2012). Digest of UK Energy Statistics (DUKES) : Load factors for renewable electricity generation.

Available:

http://www.decc.gov.uk/en/content/cms/statistics/energy_stats/source/r enewables/renewables.aspx

\section{BIOGRAPHIES}

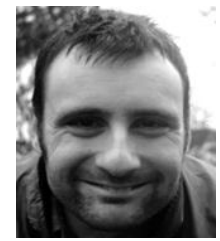

Simon Gill is currently a $\mathrm{PhD}$ candidate in the Wind Energy Centre for Doctoral Training at the University of Strathclyde. He obtained a Masters degree in Astrophysics from the University of Edinburgh in 2003, and spent four years teaching physics. His research interests include energy storage, active management of distribution networks and the integration of renewable energy into power systems.

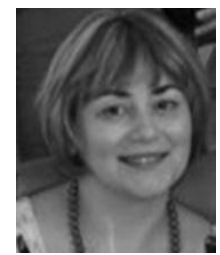

Ivana Kockar (S'99-M'04) received the

Dipl.Ing.(M.Sc.) degree from the University of Belgrade, Belgrade, Yugoslavia, and the M.Eng. and Ph.D. in 2004 from McGill University, Montreal, QC, Canada.

She is a Lecturer within the Institute for Energy and Environment at the University of Strathclyde, Glasgow, U.K. Her, research interests include power system operation planning and economics of energy systems. Dr. Kockar chairs the IEEE PES Computing and Analytical Methods Subcommittee (CAMS) and co-chairs the IEEE PES Task Force on AgentBased Modeling of Smart Grid Market Operation.

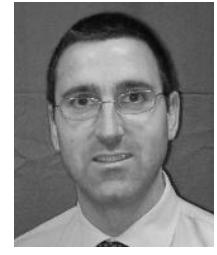

Graham W. Ault (M'98) received the B.Eng. degree in electrical and mechanical engineering and the Ph.D. degree in electrical power systems from the University of Strathclyde, Glasgow, U.K., in 1993 and 2000, respectively. Since 1996, has been researching power system planning and operations issues relating to distributed energy resources in distribution systems. He is currently a Professor in the Institute for Energy and

Environment at the University of Strathclyde. 